\title{
Contabilidade Forense e Perícia Contábil: um estudo fenomenográfico
}

\section{Forensic Accounting and Accounting Experts: A phenomenographic study}

\author{
ALINE APARECIDA DE AQUINO* \\ JOSHUA ONOME IMONIANA**
}

\section{RESUMO}

Com o aumento dos casos de corrupção e fraudes, surgiram também medidas para combater o avanço dessas práticas e restaurar a confiança dos usuários da informação. Esse contexto permitiu o desenvolvimento da prática de Contabilidade Forense, cujo foco é a prevenção e detecção de fraudes. Essa área se assemelha à outra, ligada à contabilidade, a Perícia Contábil, que, em teoria, tambémse baseia na investigação para atestar a veracidade de fatos levados a questionamento. Por isso, o presente estudo tem como objetivo identificar as similaridades entre a Contabilidade Forense e a Perícia Contábil, com foco principal nas competências exigidas de ambas as funções.Para a realização do estudo adotou-se o método de estudo fenomenográfico, cujo fundamento está na percepção que as pessoas envolvidas com determinado fenômeno têm a respeito dele. Foram realizadas entrevistas em profundidade com profissionais dessas duas áreas com o intuito de identificar a forma como eles as conceituam e também as competências exigidas para tais, a partir de três grupos: características pessoais, conhecimentos e habilidades. Com base no estudo, conclui-se que hámuitas semelhanças entre o contador forense e o perito contábil nos quesitos de julgamento e zelo profissional. Também o estudo leva a inferir que há diferenças entre o perito

* Graduada em Contabilidade pela Universidade de São Paulo e pesquisadora sobre forensic accounting e perícia contábil.

** Professor de Auditoria e Assurance\&Attestation da FEA/USP, CPA e CGeiTe Membro de Comitê IAASB de Data AnatyticAdvisoryBoard. 
e contador forense nos quesitos de experiência exigida e grau de expertise; sendo mais acentuada para o perito.

Palavras-chave: Contabilidade Forense; perícia contábil; auditoria; competências; habilidades; fenomenográfia.

\section{Abstract}

With the increase in cases of corruption and fraud, also attracted measures taken to combat the progress of such practices and restore confidence to information users. This context allowed the development the practice of forensic accounting, whose focus is the prevention and detection of fraud. This area resembles another area of accounting, historically known as accounting expert, which basicallyinvestigates and attests to the truthfulness of facts brought to question. Therefore, this study aims to identify the similarity between Forensic Accounting and Accounting Experts, with emphasis on the competencies demanded of both functions. For the accomplishment of the study it was adopted the method of phenomenological study, that is based on the perception that the people involved with a certain phenomenon has about the phenomenon itself.In-depth interviews were conducted with professionals from these two areas, in order to identify the way they conceptualize the areas and also the skills required of them, from three groups being: personal characteristics, knowledge and skills.Based on the study, it is concluded that there are many similarities between the forensic accountant and the accounting expert in questions of judgment and due professional care. Also, the study leads us to infer that there are differences between the expert and forensic accountant in the required experience and degree of expertise; this being more accentuated for the accounting expert.

Keywords: Forensic Accounting;accounting expert; audit; skills; phenomenography.

\section{INTRODUÇÃO}

Atualmente, um assunto que vem gerando grande discussão é a ocorrência de fraudes e grandes casos de corrupção. No final dos anos de 1990, a falência de uma das grandes corporações americanas, a Enron, levando consigo umas das maiores empresas de auditoria e consultoria da época, a Arthur Andersen, fez com que o mercado 
questionasse a validade e veracidade das informações contábeis apresentadas pelas companhias.

Com o intuito de combater casos como esse, o governo americano promulgou em 2002 a LeiSarbanes-Oxley. Outro objetivo era proteger o patrimônio empresarial dos sócios e investidores contra casos de fraude e corrupção, além de trazer maior transparência ao mercado. No Brasil, iniciativa parecida ocorreu com a aprovação da Lei Anticorrupção, em vigor a partir de 2013.

Nesse contexto em que o mercado exige melhor controle do patrimônio empresarial e também maior transparência, foi favorecidoo desenvolvimento de uma área da contabilidade, a chamada Contabilidade Forense, com foco em prevenção, detecção e combate a fraudes e crimes empresariais.

No Brasil, os serviços de Contabilidade Forense são prestados pelas grandes empresas de auditoria, as chamadas Big Four, que oferecem desde serviços de prevenção até aqueles relacionados à investigação de fraudes. De acordo com Vasconcellos (2016),o segmento de perícias contra fraudes contábeis tem crescido acima de três dígitos nos últimos três anos, impulsionado por três fatores interligados: a Lei Anticorrupção, aOperação Lava-Jato e o escândalo do Petrolão. Ou seja, o tema é atual e de extrema relevância.

Segundo Ribeiro (2009, p. 117), oprincipal objetivo da Contabilidade Forense é "produzir as provas da existência de uma fraude, aproximando a verdade real da verdade processual. Nesse momento a Contabilidade Forense se aproxima muito da perícia contábil. Entretanto volta-se para apuração da fraude".

Sendo assim, é necessário fazer uma distinção entre essas duas áreas, já que possuem significativas semelhanças. Além disso, é preciso distinguir também o profissional que atua nelas: o perito contador e o contador forense.

Sabendo que a Contabilidade Forense ainda é pouco explorada no país - a maior parte da produção científica, como artigos, teses e dissertações, sobre o tema é oriunda de literatura estrangeira -, este estudo tem como objetivo fazer uma análise das semelhanças entre a Perícia Contábil e a Contabilidade Forense, assim como o perfil do profissional que está à frente em cada uma delas, além de contribuir com o desenvolvimento de pesquisas a respeito dessa temática. 


\section{Questões de pesquisa}

Diante disso, levanta-se a seguinte questão de pesquisa para nortear nosso objetivo:qual é o significado da afirmação de que a Perícia Contábil e a Contabilidade Forense são similares em termos das competências profissionais exigidas?

\section{Objetivos}

Sendo assim, o objetivo principal deste estudo é mapear as variações de entendimento sobre a Contabilidade Forense e a Perícia Contábil com profissionais dessas áreas a fim de identificar as competências associadas à prática da profissão.

\section{Justificativa e contribuição do estudo}

Além disso, o estudo busca contribuir para a expansão do entendimento da Contabilidade Forense e da Perícia Contábil no país.

Pressupostos de pesquisa

O primeiro pressuposto é que:

$\mathrm{P}_{1}$ “Os fenômenos de Perícia Contábil e Contabilidade Forense partem da tradição de investigação para resolução de conflitos entre organizações".

O segundo pressuposto é que:

$\mathrm{P}_{2}$ "A Perícia Contábil e a Contabilidade Forense exigem competências similares dos profissionais que atuam nessas áreas.

\section{FUNDAMENTAÇÃo TEÓRICA}

\subsection{Perícia Contábil}

A contabilidade possui diversas vertentes e aplicações, e a Perícia Contábil se enquadra em uma delas, sendo também uma tecnologia da Contabilidade. Pois conforme afirma Sá (2011, p. 2): "A Perícia Contábil é uma tecnologia porque é a aplicação dos conhecimentos científicos da Contabilidade". 
A Perícia Contábil é utilizada em casos de conflitos entre organizações, geralmente ocasionados por disputas envolvendo questões patrimoniais, nos quais é necessário se realizar uma verificação para apurar a verdade sobre os fatos em discussão.

A Perícia Contábil é um ramo da contabilidade que serve a justiça de formasignificativa e vem tendo uma demanda crescente concernente à solução de litígios, visto que esta é um instrumento de produção de provas que está arraigada no contexto das provas permitidas na legislação. (GONÇALVES, 2013, p. 14)

A Perícia Contábil e a contabilidade se assemelham em relação ao seu objetivo, que é fornecer informações úteis para a tomada de decisões - no caso da Contabilidade, com caráter mais informativo e de prestação de contas, e na perícia, como um elemento de prova.

Sendo a perícia contábil um ramo de especialização da Contabilidade, assim como esta, aquela também é um sistema de informação para auxiliar seus usuários na tomada de decisão, ou seja, é um instrumento que serve como apoio ao Poder Judiciário quando este não dispõe de informações suficientes e necessita de conhecimento contábil específico para desencadear matéria que está sendo objeto de litígio. (GONÇALVES, 2013, p. 18)

Cabe ressaltar que serve de apoio não somente em processos judiciais, mas também extrajudiciais.

O termo perícia vem do latimperitia, que em seu sentido próprio significa conhecimento (adquirido pela experiência), bem como experiência(SÁ, 2011).

A perícia designa a diligência realizada ou executada por peritos, a fim de que se apurem, se esclareçam ou se evidenciem certos fatos. Significa, portanto, a pesquisa, o exame, a verificação acerca da veracidade ou da realidade de certos fatos, por pessoas que tenham reconhecida habilidade ou experiência na matéria de que se trata.

Para Sá (2011, p.3): 
Perícia contábil é a verificação de fatos ligados ao patrimônio individualizado visando oferecer opinião, mediante questão proposta. Para tal opinião realizam-se exames, vistorias, indagações, investigações, avaliações, arbitramentos, em suma todo e qualquer procedimento necessário à opinião.

Por último, pela definição da Norma Brasileira de Contabilidade, NBC T 13:

A perícia contábil constitui o conjunto de procedimentos técnicocientíficos destinados a levar à instância decisória elementos de prova necessários a subsidiar a justa solução do litígio ou constatação de um fato, mediante laudo pericial contábil e/ou parecer pericial contábil, em conformidade com as normas jurídicas e profissionais, e a legislação específica no que for pertinente. (CFC, [s.d.])

Dessa forma o principal objetivo de uma perícia é apresentar uma prova, a veracidade dos fatos que se relacionam com a ação, a fim de fornecer ao árbitro ou juiz o laudo pericial, para auxílio na tomada de decisões pela instância julgadora.

É no laudo pericial contábil que a perícia está fundamentada, nele estão todos os dados e informações que fundamentam a conclusão do perito. Segundo definição da Norma Brasileira de Contabilidade relacionada à Perícia Contábil, NBC TP 01:

O laudo pericial contábil e o parecer pericial contábil são documentos escritos, nos quais os peritos devem registrar, de forma abrangente, o conteúdo da perícia e particularizar os aspectos e as minudências que envolvam o seu objeto e as buscas de elementos de prova necessários para a conclusão do seu trabalho.(CFC, [s.d.])

Cabe ressaltar que a perícia pode ser judicial, feita dentro dos parâmetros do Judiciário - “[...] realizada por requerimento ou necessidade dos agentes do Poder Judiciário e devem obedecer às regras legais específicas" (SANTOS, 2012, p. 14) -, e semijudicial,realizada dentro dos procedimentos do Estado, porém fora do Poder Judiciário. 
Sua finalidade é de ser prova nos ordenamentos institucionais usuários, que podem ser policial, parlamentar (comissões de inquérito), administração tributária ou conselhos de contribuintes. É assim classificada porque estes usuários têm relativo poder jurisdicional, apenas assemelhados ao judicial. (SANTOS, 2012, p.15)

Vale ressaltar que a perícia pode ser ainda extrajudicial, sendo realizada fora do Judiciário e do aparato do Estado, ou seja, no âmbito privado.Dentro dessa categoria, tem-se a Perícia Arbitral, na qual deve ser aplicada a Lei da Arbitragem.

A arbitragem é um meio alternativo ao Poder Judiciário de resolução de conflitos que envolvam direitos patrimoniais disponíveis no qual um árbitro ou mais são escolhidos pelas partes envolvidas para solucionar a questão. A decisão do árbitro tem valor legal e deve ser obedecida, conforme art.18 da referida lei: “O árbitro é juiz de fato e de direito, e a sentença que proferir não fica sujeita a recurso ou a homologação pelo Poder Judiciário". (Lei № 9.307, de 23 de setembro de 1996 alterada pela Lei no 13.129 de 26 de maio de 2015).

Sabe-se que o Poder Judiciário brasileiro se encontra em situação alarmante, pois o número de casos levados a tal instância vem crescendo e o aparato judiciário não vem conseguindo suprir a demanda. De acordo com dados disponíveis pelo Conselho Nacional de Justiça (CNJ), a taxa de congestionamento dos processos judiciais foi de 71,4\% de 2014 para 2015 (CNJ, 2015); ou seja, além de casos abertos em anos anteriores, juntam-se aos processos milhões de novos casos a cada ano, o que ocasiona não só a superlotação de processos, mas também a demora na solução do litígio, além de desgaste entre os envolvidos.

A utilização da arbitragem vem ganhando espaço no país, mas ainda é uma área que pode ser bastante explorada. Segundo Santos (2015), houve um aumento de mais de $40 \%$ no número de casos de arbitragem no país de 2010 a 2014, e um dos motivos que tem contribuído para sua utilização é a rapidez com que uma causa é resolvida. Segundo dados apresentados pelo mesmo autor, um processo judicial leva, em média, 12 anos, ao passo que na arbitragem a mesma ação é resolvida em um ano e meio (SANTOS, 2015). 
A arbitragem relacionada a conflitos societários que envolvam questões que tenham a ver com a mensuração do patrimônio e apuração de haveres representa importante área de atuação para o profissional contábil. Isso porquenesses casos o árbitro pode optar por recorrer à Perícia Contábil, conforme estabelecido pela Lei da Arbitragem(art. 22): "Poderá o árbitro ou o tribunal arbitral tomar o depoimento das partes, ouvir testemunhas e determinar a realização de perícias ou outras provas que julgar necessárias, mediante requerimento das partes ou de ofício". Esse expediente representa uma oportunidade de atuação para o profissional contábil. (Lei № 9.307, de 23 de setembro de 1996 alterada pela Lei no 13.129 de 26 de maio de 2015).

\subsubsection{Perícia Contábil e Auditoria}

Como a Perícia Contábil e a Auditoria são áreas derivadas da Contabilidade, é comum que haja certa confusão entre esses dois temas e que alguns pensem se tratar da mesma atividade. Porém, são setores distintos, com funções e objetivos diferentes. Conforme afirma Sá (2011, p.17): "Perícia contábil não é o mesmo que auditoria contábil, pois varia em causa, efeito, espaço, tempo e metodologia de trabalho".

A partir disso, é importante destacar em quais pontos elas se diferenciam.A Perícia Contábil visa a obter provas, ou seja, atestar a veracidade de determinado fato. A Auditoria, por sua vez, é um trabalho mais de verificação.

A perícia é a "prova elucidativa dos fatos", já a auditoria é mais revisão, verificação, e tende a ser necessidade constante, repetindo-se de tempo em tempo, com menos rigores metodológicos, pois utiliza-seda amostragem. Já a perícia repudia a amostragem como critério, sendo utilizada eventualmente em casos especiais; como regra, a perícia tem caráter de labor eventual e só trabalha com o universo completo, onde a opinião é expressa com rigores de cem por cento de análise. (HOOG, 2010, p. 149)

Além de divergirem quanto aos objetivos, periodicidade e escopo de trabalho, os usuários das informações também são diferentes. Na perícia, os usuários do serviço são as partes em litígio e a Justiça ou Conselho Arbitral. Já os usuários do produto da auditoria são os só- 
cios, investidores e administradores.Porém, mesmo possuindo essas diferenças, ambas as profissões só podem ser exercidas por profissionais formados em Ciências Contábeis e registrados em Conselho.

\subsubsection{Perícia Contábil e Fraude}

Em muitos casos de Perícia Contábil o objetivo do trabalho é a detecção de fraude. Conforme afirma Sá (2011, p. 214), “fraudes contra sócios, contra herdeiros, contra o fisco, contra credores, etc. são praticadas e os peritos chamados a identificá-las".

No entanto, o trabalho de Perícia Contábil é muito mais abrangente: vai desde questões envolvendo apuração de haveres até casos de busca e apreensão, ou seja, é um campo diversificado e que permite uma infinidade de aplicações. "Onde se envolvem fatos patrimoniais de pessoas, empresas, instituições, onde esteja o diretor patrimonial está a perícia como auxiliar de primeira linha nos julgamentos" (HOOG, 2010, p.93).

Cabe ao perito comunicar a existência de fraude ou erro relevante caso esteja relacionada com o escopo de trabalho. "É perfeitamente possível que o perito informe, no item opinião, se a parte cometeu erro ou fraude contábil, desde que previsto no ponto controvertido [...]" (HOOG, 2010, p.229).

\subsubsection{O perito contábil}

Perito significa aquele que sabe, por experiência, que tem prática(NEVES JÚNIOR et al.,2015). Conforme a Norma Brasileira de Contabilidade - NBC PP01, que discorre sobre esse profissional, tem-se que é "[...] o Contador regularmente registrado em Conselho Regional de Contabilidade, que exerce a atividade pericial de forma pessoal, devendo ser profundo conhecedor, por suas qualidades e experiências, da matéria periciada" (CFC, [s.d.].

Ainda segundo a NBC PP01, o perito deve:

[...] manter adequado nível de conhecimento da ciência contábil, das Normas Brasileiras e Internacionais de Contabilidade, das técnicas contábeis, da legislação relativa à profissão contábil e aquelas aplicáveis à atividade pericial, atualizando-se, permanentemente, mediante programas de capacitação, treinamento, educação continuada e especialização. (CFC, [s.d.]) 
Além disso, segundo a mesma norma, o perito contábil deve ser capaz de:

Pesquisar, examinar, analisar, sintetizar e fundamentar a prova no laudo pericial contábil e no parecer pericial contábil [...] realizar seus trabalhos com a observância da equidade. [...] atuar com igualdade de direitos, adotando os preceitos legais e técnicos inerentes à profissão contábil. (CFC, [s.d.])

Por fim, o perito contábil deve manter sua independência e "evitar e denunciar qualquer interferência que possa constrangê-lo em seu trabalho, não admitindo, em nenhuma hipótese, subordinar sua apreciação a qualquer fato, pessoa, situação ou efeito que possam comprometer sua independência" (CFC, [s.d.]).

Vale a pena mencionar as características e habilidades profissionais do perito contábil, identificadas por meio do estudo de Gonçalves (2013). Esse autor realizou uma pesquisa com usuários da Perícia Contábil - juízes da Justiça Federal e advogados da União e os próprios peritos contadores - a fim de identificar as qualidades e habilidades fundamentais e essenciais do perito contábil. O Quadro1 foi desenvolvido com base em Gonçalves (2013) e resume os achados.

Quadro1: Características e habilidades do perito contábil

\begin{tabular}{|l|l|l|}
\hline $\begin{array}{c}\text { Traços e } \\
\text { características } \\
\text { essenciais inerentes de } \\
\text { personalidade }\end{array}$ & \multicolumn{1}{|c|}{ Habilidades fundamentais } & \multicolumn{1}{|c|}{ Habilidades mais relevantes } \\
\hline Caráter ético profissional & Eficiência na comunicação escrita & $\begin{array}{l}\text { Analisar e interpretar demonstrações } \\
\text { financeiras }\end{array}$ \\
\hline Analitico & Identificar as questões-chaves & Detecção de fraudes \\
\hline Investigador & Capacidade investigativa & Rastreamento de dados \\
\hline Criterioso & Responder os quesitos & Evidência de auditoria \\
\hline Trabalha sob pressão & Habilidade de pesquisa & Resolução de conflitos \\
\hline Sigiloso & $\begin{array}{l}\text { Habilidade de planejamento e } \\
\text { compreensão do caso }\end{array}$ & Conhecimento em direito processual \\
\hline
\end{tabular}

Fonte: Gonçalves (2013). 
Para Sá (2011, p. 9), “o perito precisa ser um profissional habilitado, legal, cultural e intelectualmente, e exercer virtudes morais e éticas com total compromisso com a verdade". Ainda segundo o autor, a capacidade legal diz respeito ao título de bacharel em Ciências Contábeis e seu respectivo registro em Conselho Regional. A capacidade profissional é caracterizada pelos seus conhecimentos práticos e teóricos em contabilidade e áreas afins, pela experiênciaem perícias, somados a atributos pessoais como perspicácia, perseverança, sagacidade e índole criativa e intuitiva. Já a capacidade ética “é a que estabelece o Código de Ética Profissional do Contador e a Norma do Conselho Federal de Contabilidade" (SÁ, 2011, p. 9). Por fim, a capacidade moral diz respeito às virtudes das atitudes pessoais do profissional.

\subsection{Contabilidade Forense}

A contabilidade fornece ao mercado, por meio da publicação das demonstrações financeiras, informações a respeito da situação patrimonial e financeira das entidades que, em teoria, devem ser úteis para a tomada de decisões de seus usuários, como acionistas, credores, investidores etc. Conforme observa Ribeiroet al.(2013, p.2): "A contabilidade, enquanto ciência social aplicada, possui como objetivo principal fornecer informações úteis, confiáveis, verificáveis, comparáveis e transparentes, visando auxiliar na tomada de decisões econômicas e avaliações de empresas por parte dos mais diversos usuários".

A contabilidade tem como objeto de estudo o patrimônio empresarial e sua principal função é informar aos seus usuários a situação patrimonial de uma entidade e a sua evolução. “[...] o patrimônio de uma entidade, os fenômenos que o afetam, o usuário da informação sobre esse patrimônio e o seu modelo decisório são os objetos de estudo da Contabilidade [...]" (BORINELLI; PIMENTEL, 2010, p.7).

Nos últimos anos, com a ocorrência de fraudes e escândalos envolvendo grandes empresas, como a americana Enron, houve no mercado uma crise de confiança com relação aos sistemas de controle interno das empresas e também à qualidade das informaçõesdivulgadas por elas; ou seja, até que ponto as informações prestadas por uma organização são dignas de confiança. 
Nesse contexto surgiu a área da Contabilidade Forense, cujo foco de atuação está na prevenção, detecção e apuração de fraudes. Conforme Silva (2012, p.37):

[...] a perda de credibilidade no ambiente corporativo provocou, nos últimos anos, o fortalecimento de outro campo de trabalho para auditores e contadores: o da contabilidade forense, que consiste na integração das habilidades contábeis, investigativas e de auditoria. Tal conhecimento possibilita o fornecimento de auxílio, em litígios judiciais ou em investigações sobre suspeitas de fraudes e irregularidades, além do rastreamento sobre a origem e o destino de grandes somas, seja em dinheiro ou em outros ativos desviados das entidades.

A contabilidade forense tem como foco a investigação, a detecção e a prevenção de fraudes e crimes econômicos.

A Contabilidade Forense se apresenta como uma evolução do processo de controle do patrimônio, expandindo suas fronteiras além da coleta, do registro e da divulgação das informações contábeis. Dessa forma, ao se tornar a ciência responsável pelo combate à fraude, qualificase como estrutura capaz de produzir provas hábeis e admissíveis em Juízo, implicando o domínio de conhecimentos contábeis, de procedimentos de investigação especiais e multidisciplinares, inclusive. (CARDOSO, 2008, p. 9)

Esse ramo da Contabilidade conta com informações das mais diversas áreas do conhecimento e se baseia na investigação. Sendo assim a Contabilidade Forense é:

[...] uma especialidade da ciência contábil de natureza interdisciplinar, a qual combina conhecimentos da contabilidade, da criminologia, da psicologia, da semiótica, do direito e das finanças, com o objetivo de prevenir e reprimir a fraude e todos os crimes de naturezaeconômicofinanceiros, a exemplo da lavagem de capitais.(RIBEIROet.al., 2013, p.2)

A Contabilidade Forense utiliza técnicas e procedimentos de auditoria na evidenciação e detecção de fraudes. 
Contabilidade Forense é uma ciência que lida com fatos contábeis reunidos por meio de métodos e procedimentos de auditoria aplicados a problemas de ordem legal, usualmente afetos a questões contábeis e de avaliação. É significativamente diferente da auditoria tradicional, sendo que as evidências obtidas devem ser capazes de serem apresentadas em ambiente judicial. (GRIPPO; IBEX, 2003, citado por CARDOSO, 2008, p. 15)

As evidências obtidas podem ser levadas em esfera judicial, no entanto a maioria das empresas prefere que casos que envolvam fraude sejam resolvidos internamente, como uma forma de preservar sua imagem. “O contador forense pode até testemunhar em juízo ou perante uma autoridade julgadora, mas essa não é sua finalidade" (RIBEIRO, 2009, p.124).

Quando o assunto é Contabilidade Forense, é preciso destacar o conceito de fraude contábil para poder entendê-la melhor.

\subsubsection{Fraudes contábeis}

“O termo fraude tem origem no latim fraus e indica ação praticada de má-fé, abuso de confiança, contrabando, clandestinidade ou falsificação e adulteração"(SILVA,2012, p.11).A Norma Brasileira de Contabilidade Interpretação Técnica NBC T 11-IT conceitua fraude como sendo: "ato intencional de omissão ou manipulação de transações, adulteração de documentos, registros e demonstrações contábeis" (CFC, [s.d.]).

Pesquisa realizada pela KPMG em 2015 indica que 70\% dos empresários sofreram fraude em sua companhia entre 2013 e 2015. Entre os principais motivos foram citados a falsificação de cheques e documentos (por 29\% dos entrevistados) e roubo de ativos (por 25\%). Além disso, o levantamento revelou que para $61 \%$ dos entrevistados, o maior potencial para a prática de fraudes existe dentro da própria organização, incluindo a alta administração e os demais funcionários.

Sendo assim, cada vez mais as empresas precisam encontrar formas de prevenir e combater as fraudes no ambiente corporativo, o que é um grande desafio. De acordo com pesquisa da KPMG (2016) sobre o perfil do fraudador, as recomendações para o combate à fraude são realizar avaliações de risco, utilizar a tecnologia 
a favor da empresa, conhecer os parceiros de negócio e terceiros e ficar atento às ameaças internas.

\subsubsection{0 contador forense}

Com o surgimento da Contabilidade Forense, com suas especificidades, é necessário encontrar profissionais com um perfil diferente do atual contador para suprir essa nova demanda de serviço. É assim que surge a figura do contador forense:

Os contadores forenses são vistos como uma combinação do profissional auditor e do investigador privado. Dessa forma, os conhecimentos e habilidades mais comuns nesses profissionais são: habilidade de investigação, pesquisa e levantamento de dados, conhecimentos jurídicos, métodos quantitativos, finanças, auditoria e contabilidade. (RIBEIROet al., 2013, p.7)

O trabalho do contador forense se inicia a partir do momento em que há um indício de fraude que precisa ser apurado, indo além da investigação e analisando os impactos que isso pode causar à empresa.

O contador forense pode prestar apoio processual tanto na fase de produção de provas, como na fase de perícia propriamente dita. Seu trabalho se destaca nas investigações em curso, bem como na prevenção de fraudes, tendo por finalidade não somente a investigação propriamente dita, mas determinar a quantia desviada através de um delito econômico. (RIBEIRO, 2009, p.111)

De acordo com AssociationofCertifiedFraudExaminers (ACFE, 2012), são responsabilidades únicas do contador forense:

- Realizar pesquisa forense para rastrear fundos e identificar ativos para recuperação;

- Realizar análises forenses de dados financeiros;

- Preparar relatórios de contabilidade forense de resultados financeiros;

- Preparar dados analíticos para litígios e testemunha conforme necessário. 
Algumas competências geralmente associadas ao contador forense são primeiramente o conhecimento em Contabilidade, além da interpretação das demonstrações financeiras, habilidades investigativas e habilidades de realizar entrevistas. Além disso, uma série de outros atributos também é requerida desse profissional, conforme exposto no Quadro 2.

Quadro 2: Habilidades do contador forense

\begin{tabular}{|l|}
\hline \multicolumn{1}{|c|}{ Habilidades } \\
\hline Comunicação interpessoal \\
\hline Comunicação verbal \\
\hline Comunicação escrita \\
\hline Atenção a detalhes \\
\hline Analitico \\
\hline Integridade \\
\hline Objetividade \\
\hline Independência \\
\hline Credibilidade \\
\hline
\end{tabular}

Fonte:Elaborado pela autora com base em ACFE (2012).

\section{Procedimentos metodológicos}

Para se analisar a relação entre as competências e habilidades do contador forense edoperito contábil, além das similaridades e diferenças entre as duas profissões, adotou-se o método de pesquisa fenomenográfico conforme utilizado pelos Brunstein, Heidrich e Amaro (2016).

Segundo Imoniana e Silva (2013), a análise filosófica e social enfoca enfaticamente o fenômeno como talvez as fontes mais importantes no cultivo de uma conscientização coletiva de fraude corporativa e segue o modelo que demonstra o W5H (O que, Por que, Quem, Onde e Quando) da fraude corporativa.

A justificativa para a escolha desse método reside no fato de que a bibliografia hoje existente com relação ao profissional da Perícia Contábil se baseia em normas e procedimentos técnicos a respeito 
de como este deve realizar seu trabalho. A literatura a respeito do contador forense ainda é pouco exploradaem nível nacional, e a maior parte dos achados sobre a profissão se encontra em literatura estrangeira. Sendo assim, aplicou-se esse métodoa fim de identificar a forma como esses profissionais enxergam as suas profissões e também as competências e habilidades que percebem como necessárias para o exercício delas.

Segundo Martins e Theóphilo (2007, p.44), “a fenomenologia fundamenta-se na busca do conhecimento a partir da descrição das experiências como estas são vividas, não havendo separação entre sujeito e objeto".

Esse método de pesquisa busca entender o processo de aprendizagem e desenvolvimento de competências por meio das experiências dos indivíduos na execução de uma atividade. Ou seja, intenta compreender a experiência de umapessoa ao se relacionar com determinado fenômeno a fim de compreender o fenômeno em questão. "Conhecer o espaço de resultados de um determinado fenômeno propicia pensar o desenvolvimento a partir da mudança da maneira de conceber esse mesmo fenômeno" (AMARO; BRUNSTEIN, 2011, p.9).

Esta pesquisa tem também caráter qualitativo, já que se utiliza da coleta de dados qualitativos, descrições e observações que apoiam o processo de interpretação.

Sendo assim, foram realizadas quatro entrevistas, uma delas por e-mail. Foram entrevistados dois profissionais da área de Perícia Contábil com anos de experiência diferenciados e que trabalham em escritório especializado, além de outrasduas entrevistascom profissionais de Contabilidade Forensededuas das quatro grandes empresas de auditoria e consultoria (Big Four), também com anos de experiência diferenciados na área.

As entrevistas se deram entre outubro e novembro de 2016 e tiveram como objetivoverificar a forma como esses profissionaisdefinem os temas abordados, como vivenciam os fenômenos na prática e que competências identificam como necessárias para o exercício da profissão, para assim serem percebidas semelhanças e diferenças entre eles. 


\section{ANÁlise DE RESUltados}

Conforme exposto na metodologia, foram entrevistados quatro profissionais das áreas de Contabilidade Forense e Perícia Contábil, com diferentes tempos de experiência. O Quadro 3 resume esses dados. Nele, foram dados nomes fictícios aos respondentes.

Quadro3: Informações sobre os entrevistados

\begin{tabular}{|c|l|r|}
\hline Entrevistado & \multicolumn{1}{|c|}{ Área de Atuação } & $\begin{array}{c}\text { Tempo de } \\
\text { experiência na área }\end{array}$ \\
\hline João & Perícia Contábil & 40 anos \\
\hline Maria & Perícia Contábil & 1 ano e meio \\
\hline José & Contabilidade Forense & 4 anos \\
\hline Pedro & Contabilidade Forense & 23 anos \\
\hline
\end{tabular}

Fonte: Dados da pesquisa.

Um dos objetivos do trabalho era identificar as concepções sobre a Perícia Contábil e a Contabilidade Forense, do ponto de vista dos profissionais que atuam nessas áreas. Para facilitar a comparação entre os dois conceitos, foi elaborado oQuadro 4 com base nas diferentes percepções dos entrevistados.

\section{Quadro 4: Concepções de Perícia Contábil e Contabilidade Forense}

\begin{tabular}{|c|c|}
\hline Perícia Contábil & Contabilidade Forense \\
\hline $\begin{array}{c}\text { Exame investigativo integral de matéria que } \\
\text { dependa de conhecimento da ciência contábil } \\
\text { efetuado por contador e destinado a esclarecer } \\
\text { técnicos e leigos }\end{array}$ & Técnicas de coleta de prova de um crime \\
\hline Produto do conhecimento do contador & $\begin{array}{l}\text { É a utilização de conhecimentos de } \\
\text { contabilidade e técnicas de auditoria para a } \\
\text { investigação }\end{array}$ \\
\hline Informação & Investigação \\
\hline Traduzir o conhecimento técnico para o leigo & $\begin{array}{l}\text { A combinação de um trabalho de perícia e } \\
\text { investigação contábil com o fim de determinar, } \\
\text { prevenir e identificar a ocorrência de crimes } \\
\text { dentro das empresas. }\end{array}$ \\
\hline
\end{tabular}

Fonte: Dados da pesquisa. 
Com base nos diferentes conceitos apresentados pelos entrevistados, é possível observar que quando se trata de Perícia Contábil, ela está intrinsecamente relacionada com conhecimento. Já quando o assunto é Contabilidade Forense, as concepções apontam o caráter investigativo da profissão.

Quando perguntados se enxergavam relações entre as duas áreas, o resultado foi unânime: todos identificavam alguma relação entre elas. Dois dos entrevistados, João e José,responderam que uma complementa a outra, afirmando que o trabalho se inicia com a investigação, realizada pela área forense, e pode terminar com a perícia, quando o ato é levado a julgamento. O senhor José foi mais além e disse o seguinte: "A Contabilidade Forense e a Perícia contábil se utilizam de técnicas de auditoria para a realização dos seus trabalhos, mas com focos diferentes".

Foi afirmado por todos os entrevistados que elas se diferenciam quanto a seus objetivos. Segundo o senhor Pedro, a Contabilidade Forense e a Perícia Contábil apresentam: "Muita semelhança quando o crime já ocorreu e tentamos saber o que aconteceu e quem praticou. Pouca semelhança quando estamos investigando o que aconteceu".

Cabe ressaltar que os assuntos e questões apresentados a esses profissionais diferem, ressaltando a ideia de que as áreas possuem objetivos distintos. Na área de Perícia Contábil são levados os mais diversos temas, que vão desde questões governamentais e empresariais até familiares. Os principais assuntos que requerem a Contabilidade Forense, por sua vez, estão relacionados com a prevenção e a detecção de fraudes e corrupção.

Uma vez definidos os dois fenômenos, buscou-se verificar, a partir da experiência dos entrevistados, quais seriam as competências e habilidades associadas a essas profissões e as características necessárias para exercê-las,conforme pode ser observado no Quadro 5. 
Quadro 5: Perfil profissional do perito contábil e do contador forense

\begin{tabular}{|l|l|}
\hline \multicolumn{1}{|c|}{ Perito Contábil } & \multicolumn{1}{c|}{ Contador Forense } \\
\hline Ler e escrever bem & Excelente redação \\
\hline Envolvido com o mercado & Conhecimento das leis sobre crime \\
\hline De 2 a 5 anos de adaptação & Criminologia \\
\hline Probidade & Perícia Contábil \\
\hline Honestidade intelectual & Auditoria \\
\hline Integridade / Valores & Contabilidade \\
\hline Conhecimento profundo em Contabilidade & Análise de dados \\
\hline Saber fazer perguntas & Capacidade de entrevistar e coletar informações \\
\hline Trabalho em equipe & Saber pesquisar banco de dados \\
\hline Dosar humildade e não subserviência & Integridade \\
\hline Profissional aberto a aprender & Senso crítico \\
\hline Conhecimento juridico & Valores morais \\
\hline $\begin{array}{l}\text { Experiência com auditoria externa, investigação e } \\
\text { compliance }\end{array}$ & Profissional aberto a aprender \\
\hline Expert & Analitico (raciocínio lógico) \\
\hline Estar perito & Experiência profissional em auditoria externa \\
\hline
\end{tabular}

Fonte: Dados da pesquisa.

Os entrevistados responderam à questão de forma aberta, e o resultado verificado foi que a maioria das características que os profissionais das áreas em estudo elencaram estão relacionadas e são muito semelhantes.

De acordo com os dados, o perfil profissional de ambos é muito semelhante, no entanto apresentam algumas diferenças expressivas, por exemplo, com relação ao grau de experiência que difere um perito contador de um contador forense. Embasado nas entrevistas, o perito contábil é um expert em Contabilidade, com vasta experiência em auditoria externa, investigação e compliance, além de sólidos conhecimentos na área jurídica. Para a senhora Maria:“Os peritos são os óculos para o juiz ou árbitro".

Para se exercer a Perícia Contábil, de acordo com as entrevistas, é necessário um longo tempo de adaptação à profissão. Dos entrevistados, a senhora Maria está no processo de adaptação, que segundo o senhor João vai de dois a cinco anos. Ele afirma que esse 
período é importante por conferir maior segurança e qualidade ao trabalho pericial.

De acordo com o que foi constatado, o perfil do contador forense se assemelha ao do perito contador. As competências levantadas pelos entrevistados podem ser divididas em três grupos distintos: o das características pessoais dos profissionais; o dos conhecimentos necessários para exercício da profissão; e o das habilidades necessárias dos profissionais que atuam nas áreas em estudo. As características profissionais levantadas pelos entrevistados foram organizadas em cada um dos grupos de competências de forma a fazer uma comparação entre o perfil profissional do contador forense e do perito contábil, com base nos aspectos em que são semelhantes, conforme mostra o Quadro 6.

Quadro 6: Competências associadas à Perícia Contábil e à Contabilidade Forense

\begin{tabular}{|l|l|l|}
\hline \multicolumn{1}{|c|}{$\begin{array}{c}\text { Características } \\
\text { pessoais }\end{array}$} & \multicolumn{1}{c|}{ Conhecimentos } & \multicolumn{1}{c|}{ Habilidades } \\
\hline Integridade & Contabilidade & $\begin{array}{l}\text { Ler e escrever com } \\
\text { excelência }\end{array}$ \\
\hline Valores morais & Conhecimento juridico & $\begin{array}{l}\text { Capacidade de entrevistar } \\
\text { e coletar informações }\end{array}$ \\
\hline Senso crítico & $\begin{array}{l}\text { Experiência com } \\
\text { auditoria externa }\end{array}$ & $\begin{array}{l}\text { Ser aberto a aprender e se } \\
\text { reciclar }\end{array}$ \\
\hline
\end{tabular}

a) Características pessoais: com relação às características pessoais apresentadas, destacam-se a integridade, os valores morais e o senso crítico. Tais características são intrínsecas às pessoas. Com relação à integridade, o exposto durante as entrevistas foi que ambos os profissionais devem ser honestos e não deixar que nada venha a influenciar a boa execução do trabalho, ou seja, que nenhuma influência externa possa corromper o trabalho, comosuborno e outras práticas. Com relação aos valores morais, foi constatado que é imprescindível que ambos os profissionais tenham os valores morais bem estabelecidos e sólidos, para evitar casos como o mencionado 
anteriormente, mas tais valores não devem interferir na investigação. Por exemplo, tanto na Perícia Contábil quanto em Contabilidade Forense o profissional não deve permitir que seus valores pessoais e julgamentos interfiram na atividade. Ambos devem investigar fatos e não suposições. Ambas as características estão inter-relacionadas e embasam também a característica de senso crítico, pois é necessário que o profissional não leve em conta o senso comum, mas atue de forma a analisar o que foi proposto.

b) Conhecimentos: para ambos os profissionais foram requeridos conhecimentos em Contabilidade, conhecimento jurídico e experiência com auditoria externa. Com relação a conhecimentos na área contábil, já era esperado, pois asduas profissões são derivadas dessa área. O conhecimento vai mais além, pois é necessário que os profissionais saibam analisar demonstrações financeiras e as contas que as compõem, além de ter um bom conhecimento de mercado. Já com relação ao conhecimento jurídico, é essencial que tenham conhecimentos de leis e também do próprio procedimento jurídico. Por último, foi levantada a experiência com auditoria externa, pois esta dá uma visão do todo empresarial e foi identificada nas entrevistas como um início do caminho da investigação e perícia.

c) Habilidades:é necessário que ambos, o perito contador e o contador forense, escrevam e leiam bem, pois sua análise deve ficar clara para que seu objetivo seja alcançado. Uma comunicação ineficiente torna o trabalho desses profissionais menos compreensível, podendo até resultar em perda de credibilidade. Outra habilidade importante é saber entrevistar e coletar informações, pois em ambos os casos os profissionais trabalham com prazos e devem ser eficientes e eficazes na utilização dos recursos à disposição. Por último, no entanto de extrema importância, é a capacidade de se manter atualizado e ser aberto a aprender, pois ambos os trabalhos são dinâmicos e é essencial que o profissional também o seja.

\section{DISCUSSÃo}

De acordo com os resultados da pesquisa, primeiramente é necessário que tanto o profissional que atua com Contabilidade Forense quanto o que atua em Perícia Contábil sejam honestos e íntegros. Isso é imprescindível, pois ambas as profissões os expõem 
a situações em que podem ocorrer tentativas de suborno ou outras formas de manipulação do seu trabalho, daí a importância dessas características.

Foram identificadas semelhanças entre esses profissionais com relação às competências exigidas, mas também se evidenciaram diferenças entre eles, principalmente quanto ao grau de expertise do perito, que deve ser um grande conhecedor do assunto a que se propõe analisar. Por exemplo, pode ser citado um caso apresentado durante a aula de Auditoria e Perícia Contábil na FEA/USP, em que determinado juiz preferiu a convocação de uma nutricionista para analisar um processo de perícia em restaurantes a indicar um perito contador, pelo fato de o grau de entendimento da nutricionista sobre o assunto ser maior.

À primeira vista, muitos podem dizer que tanto a Perícia Contábil quanto a Contabilidade Forense tratam dos mesmos assuntos. Porém, de acordo com os resultados da pesquisa, ainda que ambas possuam bastantes semelhanças como, por exemplo, se basearem na investigação para a resolução de conflitos e os profissionais terem perfis semelhantes, é possível identificar grandes diferenças entre elas.

Uma delas seria o escopo de atuação da Perícia Contábil, que é bem mais abrangente do que o campo de atuação da Contabilidade Forense. Esta se concentra mais em casos de prevenção e combate a fraudes, ao passo que aa outra possui um leque diverso de atuação, indo desde questões simples, como casos familiares, até aquelas mais complexas, como apuração de haveres entre sócios. Outra diferença marcante é a sua motivação, pois na Perícia Contábil o foco é apresentar prova de algum acontecimento perante um órgão julgador, ao passo que na Contabilidade Forense precisa-se obter prova que não necessariamente vai ser utilizada em meio jurídico ou arbitral.

Cabe destacar também que a prática da Perícia Contábil no Brasil é regulamentada e possui uma gama de normas que regem a profissão, ao passo que a Contabilidade Forense não possui esse grau de regulação no país. Com base na situação atual do país e com casos de fraudes e corrupções aumentando consideravelmente, esse profissional vem se tornando cada vez mais demandado nos últimos anos e ganhando maior destaque, tendência apontada em 
artigo veiculado no "Jornal Valor Econômico". Conforme apresentado anteriormente, é possível que a profissão do contador forense se torne regulamentada nos próximos anos.

\section{CONSIDERAÇõES FINAIS}

Adotando-se o método de pesquisa fenomenográfico, por meio de entrevistas com profissionais que atuam nas áreas de Perícia Contábil e Contabilidade Forense, foi possível identificar que guardam grandes semelhanças entre si, apesar de terem focos diferentes.

O pressuposto 1, de que os fenômenos de Perícia Contábil e da Contabilidade Forense partem da tradição de investigação para resolução de conflitos entreorganizações, éverdadeiro, pois ambas se sustentam na amenização de conflitos entre os indivíduos. No entanto, a investigação é realizada de forma diferente e com objetivos distintos:na Perícia Contábil o objetivo é atestar a veracidade de informações perante um julgador, já na Contabilidade Forense o foco é a identificação da ocorrência da fraude, como uma prova que, no entanto, não necessariamente é levada à instância julgadora. Muitas empresas preferem realizar essas investigações de forma fechada e solucionar a questão internamente para preservar sua imagem no mercado.

Já com relação ao perfil profissional dos profissionais das áreas de Contabilidade Forense e de Perícia Contábil, conforme o pressuposto 2, de que tais áreas exigem competências similares dosprofissionais que nelas atuam,foi possível identificar que os tais profissionais possuem características pessoais, conhecimentos e habilidades semelhantes. Éesperado que sejam íntegros, tenham valores morais robustos e senso crítico, além de conhecerem a fundo Contabilidade, aspectos jurídicos e terem experiência com auditoria externa. Também é necessário que saibam se comunicar de forma eficiente, tanto na forma escrita quanto na falada, além de terem capacidade de entrevistar e coletar informações e se manterem atualizados.

Com base no estudo, conclui-se que há muitas semelhanças entre o contador forense e o perito contábil nos quesitos de julgamento e zelo profissional. Também a pesquisa leva a inferir que há diferenças nos quesitos de experiência exigida e grau de expertise; sendo mais acentuada para o perito. 
É importante destacar ainda que a produção literária brasileira, quando se trata de Contabilidade Forense, ainda é um tanto precária. São poucos os autores que se aprofundam no tema, e seria interessante que mais pessoas se voltassem a ele, pois é muito atual e representa uma demanda crescente no mercado empresarial, além de uma área de atuação para os formados em Contabilidade.

Enfim, como sugestão para pesquisa futura cabe ressaltar que os dados aqui apresentados tiveram como base uma pequena amostra e que seria interessante expandir a pesquisa para um número maior de entrevistados, abordando também outros aspectos, que não apenas o perfil profissional do perito contador e o contador forense, mas as técnicas que ambos utilizam para a execução dos trabalhos, por exemplo.

\section{REFERÊNCIAS}

ACFE - ASSOCIATION OF CERTIFIED FRAUD EXAMINERS. Report to the Nations. On Occupational Fraud and Abuse. Global Fraud Study. 2012. Disponível em: < https://www. acfe.com/uploadedFiles/ACFE_Website/Content/rttn/2012-report-to-nations.pdf $>$. Acesso em: 03/08/2016.

AMARO, R. A.; BRUNSTEIN, J. As contribuições da fenomenografia para o desenvolvimento da competência profissional nas organizações. In: ENCONTRO DE GESTÃO DE PESSOAS E RELAÇÕES DE TRABALHO, 3., João Pessoa, 2011. Anais... Rio de Janeiro: ANPAD, 2011. Disponível em: < http://www.anpad.org.br/admin/pdf/2011_ENGPR105.pdf >. Acesso em: 10/09/2016.

BORINELLI, M. L.; PIMENTEL, R. C. Curso de Contabilidade para gestores, analistas e outros profissionais. São Paulo: Atlas, 2010.

BRASIL. Lei n. 9.307, de 23 de setembro de 1996. Diário Oficial da União, Poder Legislativo, Brasília, DF, 24 set. 1996. Disponível em: <http://www.planalto.gov.br/ccivil_03/leis/L9307. htm>. Acesso em 18/06/2016.

BRASIL. Lei no 13.129, de 26 de maio de 2015. Disponível em <http://www.planalto.gov.br/ ccivil_03/_Ato2015-2018/2015/Lei/L13129.htm> Acesso em 18/06/2016.

BRUNSTEIN, J.; HEIDRICH, S. B.; AMARO, R. A. Competencies for a Fair Play in organizations: a phenomenographic analysis of managers. Brazilian Business Review, Vitória, v. 13, n. 2, p. 105-134, 2016.

CARDOSO, F. N. Contabilidade forense no Brasil: incipiência ou insipiência? 67 f. Dissertação (Mestrado em Ciências Contábeis) - Programa Multi-institucional e Inter-Regional de Pós-graduação em Ciências Contábeis, Universidade de Brasília, Universidade Federal da Paraíba, Universidade Federal de Pernambuco, Universidade Federal do Rio Grande do Norte, Brasília, 2008. 
CFC - CONSELHO FEDERAL DE CONTABILIDADE. Resolução n. 1.244, de 10 de dezembro de 2009. Conselho Federal de Contabilidade. Brasília, 2009.

. Norma Brasileira de Contabilidade NBC PP 01 - Perito Contábil. Disponível em: <http://portalcfc.org.br/wordpress/wp-content/uploads/2013/01/Per\%C3\%ADcia_ Cont $\%$ C3\%A1bil.pdf $>$. Acesso em 27/06/2016.

. Resolução n. 1.243, de 10 de dezembro de 2009.Conselho Federal de Contabilidade. Brasília, 2009.

. Norma Brasileira de Contabilidade NBC TP 01 - Norma Técnica de Perícia Contábil. Disponível em: <http://portalcfc.org.br/wordpress/wp- content/uploads/2012/12/NBC_TP_01. pdf>. Acesso em 27/06/2016.

. Resolução n. 836, de 22 de fevereiro de 1999. Conselho Federal de Contabilidade. Brasília, 1999.

. Norma Brasileira de Contabilidade Interpretação Técnica NBC T 11 IT 03 - Fraude

e Erro. Disponível em: <http://www.portaldecontabilidade.com.br/nbc/t1103.htm>. Acesso em 27/06/2016.

Resolução n. 858, de 21 de outubro de 1999.Conselho Federal de Contabilidade. Brasília, 1999.

Norma Brasileira de Contabilidade NBC T 13 - Perícia Contábil. Disponível em: $<$ http://www.portaldecontabilidade.com.br/nbc/t13.htm>. Acesso em 27/06/2016.

CNJ - CONSELHO NACIONAL DE JUSTIÇA.Justiça em números 2015.YouTube.com, 21 set.2015. Disponível em: <https://www.youtube.com/watch?v=N6Hlbt1eXos>. Acesso em 25/06/2016.

GONÇALVES, P. C. Características do perito contador: perspectiva segundo os juízes da Justiça Federal, advogados da União e peritos contadores no contexto goiano. $51 \mathrm{f}$. Trabalho de Conclusão de Curso (Bacharelado em Ciências Contábeis) - Universidade Federal de Goiás, Goiânia, 2013. Disponível em: <http://repositorio.bc.ufg.br/bitstream/ri/319/1/Patricia\%20 Celestino\%20Gon\%C3\%A7alves.pdf>. Acesso em 08/09/2016.

HOOG, W. A. Z. Prova pericial contábil: Teoria e Prática. Curitiba: Juruá Editora, 2010.

IMONIANA, J. O.; SILVA, R. M. Revisiting the concepts of forensic accounting and

corporate fraud. Int. J. Auditing Technology, v. 1, n. 2, p. 175-202, 2013.

KPMG. Perfil global do fraudador: A tecnologia viabiliza e os controles deficientes estimulam a fraude. 2016. Disponível em: <http://s.conjur.com.br/dl/perfil-fraudador-2016-kpmg.pdf >. Acesso em 29/10/2016.

MARTINS, G. de A.; THEÓPHILO, C. R.Metodologia da Investigação Científica para as Ciências Sociais Aplicadas. São Paulo: Atlas, 2007.

NEVES JÚNIOR, I. J. das; FLORIDO, M. A. B.; ESTEVES, V. P.; BARRETO, M. D. Perícia Contábil: Fatores utilizados para a escolha e na manutenção de peritos contadores como peritos do Juízo, na opinião dos magistrados do Estado do Rio de Janeiro. In: CONGRESSO NACIONAL DE ADMINISTRAÇÃO E CONTABILIDADE, 6., Rio de Janeiro, 29-30 out. 2015. 
Anais...Rio de Janeiro: Adcont, 2015.Disponível em: <http://www.adcont.net/index.php/adcont/ adcont2015/paper/viewFile/1891/473>. Acesso em 09/09/2016.

RIBEIRO, A. A. D.Contabilidade Forense e lavagem de capitais: um estudo da percepção da relevância da Contabilidade Forense nas investigações de organizações criminosas. 245 f. Dissertação (Mestrado em Ciências Contábeis) - Universidade Federal de Pernambuco, Recife,2009. Disponível em: <https://www.ufpe.br/ppgcontabeis/images/documentos/Dissertacoes/arnaldo\%20antonio\%20duarte\%20ribeiro\%2023\%2011\%2009.pdf>. Acesso em 10/09/2016.

RIBEIRO, A. A. D.; RODRIGUES, R. N.; LAGIOIA, U. C. T.; CASTRO, M. N. Contabilidade forense: Um estudo perceptivo na relevância da Contabilidade Forense na investigação de lavagem de capitais praticadas por organizações Criminosas. In: CONFERÊNCIA INTERAMERICANA DE CONTABILIDADE, 30., Punta del Este, 2-3 dez.2013. Anais... Punta del Este:Colégio de Contadores, Economistas e Administradores do Uruguai, 2013. Disponível em:<http://www.cpcecba.org.ar/media/img/paginas/Contabilidade $\% 20$ Forense. $\% 20 U m \% 20$ Estudo\%20Perceptivo\%20Na\%20Relev\%C3\%A2ncia\%20Da\%20Contabilidade\%20Forense \%20 Na\%20Investiga\%C3\%A7\%C3\%A3o\%20De\%20Lavagem\%20De\%20Capitais\%20Praticadas\%20 Por\%20Organiza\%C3\%A7\%C3\%B5es\%20Criminosas.pdf>. Acesso em 09/09/2016.

SÁ, A. L. de. Perícia Contábil. São Paulo: Atlas, 2011.

SANTOS, G. Arbitragem ganha espaço para resolver conflito de empresas. Folha de São Paulo, 12 jan. 2015. Disponível em: <http://www.siqueiracastro.com.br/Noticias/SCAMidia/Folha\%20 de $\% 20$ S $\%$ C3\%A3o\%20Paulo\%20-\%20Arbitragem \%20ganha\%20espa\%C3\%A7o\%20para $\% 20$ resolver\%20conflito\%20de\%20empresas\%20-\%2012-01-2015.pdf>. Acesso em 09/09/2016.

SANTOS, R. P. Perícia Contábil. Maringá: Centro Universitário de Maringá, 2012. [Apostila]. SILVA, L. M. da. Contabilidade Forense: Princípios e Fundamentos. São Paulo: Atlas, 2012. VASCONCELLOS, C.Controle Acurado. Valor Econômico, 21 out. 2016. Disponível em: <http:// www.valor.com.br/empresas/4751239/controle-acurado>. Acesso em: 20/11/2016.

Recebido em: 23-12-2016

Aprovado em: 24-4-2017

Avaliado pelo sistema double blind review.

Editor: Elmo Tambosi Filho

Disponível em http://mjs.metodista.br/index.php/roc 